\title{
XLV. On irregularities observed in the direction of the compass needles of H. M. SS. Isabella and Alexander, in their late voyage of discovery, and caused by the attraction of the iron contained in the ships
}

\section{Captain Edward Sabine F.R.S.}

To cite this article: Captain Edward Sabine F.R.S. (1819) XLV. On irregularities observed in the direction of the compass needles of H. M. SS. Isabella and Alexander, in their late voyage of discovery, and caused by the attraction of the iron contained in the ships, Philosophical Magazine Series 1, 54:258, 276-282, DOI: 10.1080/14786441908652226

To link to this article: http://dx.doi.org/10.1080/14786441908652226

曲 Published online: 29 Jul 2009.

Submit your article to this journal ¿

Џll Article views: 2 
XLV. On Irregulurities olserved in the Direction of the Compass Needles of H.M.SS. Isabella and ALEXaNDER, in their late Voyage of Discovery, and caused by the Attraction of the Iron contained in the Ships. By Caplain Edwaro SaBIne, of the Royal Regiment of Artillery, F.R.S. EंC.*

$\Pi_{T}$ is proposed in this paper to show in what respects the effects of local attraction, in the abovementioned ships, were conformable to the observations which had been made in preceding voyages; and how far the errors, which were found to take place on different courses, and under different dips of the magnetic needle, corresponded with the rules for calculating corrections, which Captain Flinders had found useful in his own experience, and which he had recommended for a more extensive trial.

It may be desirable to premise, that the irregularities here alluded to, are not those accidental disturbances which may be caused by iron placed inadvertently too near the compasses; but the permanent and constant effect of the mass of iron contained in a ship, affecting its compasses at all times, and in a greater or less degree, according as its influence is more or less powerful, in comparison to the directive force of the earth's magnetism. That errors have always existed from this cause, 'may be inferred, from the uncertainty which experience has attached to the results of azimuths observed in ships. The cause, however, appears to have been very long unsuspected, whilst its effects had produced a general impresssion, that the azimuth compass was in itself an imperfect instrument, and only to be relied on within certain undefined and variable limits.

It was reserved to the accurate observation, and the habit of recording and comparing apparently trivial and accidental differences in results, which distinguished the late $\mathrm{Mr}$. Wales, (astronomer in the second voyage of Captain Cook,) to enable him to lead the way to a knowledge of the nature and causes of these errors: he remarks, "that in the passage of the Resolution and Adventure to the Cape of Good Hope, and subsequently, the greatest west variations had happened when the ship's head was north and easterly, and the least when it was south and westerly, differing very materially from one another with the ship's head in different positions, and still more when observed in different ships ;" thus manifesting that they were something more than accidental.

This voyage was the last in which Mr. Wales embarked, and the investigation does not appear to have been pursued in this country until the voyage of discovery to Terra Australis, in the

* From the Philosophical Transactions for 1819, Part I. 
first years of the present century. The survey of the coast of New Holland being carried on in a considerable measure by the intersection of compass bearings taken from the deck of the Investigator, so much embarrassment and perplexity were found to arise from the effects of local attraction, that much of Captain Flinders's attention and thoughts were necessarily devoted to a consideration of some means of remedying the inconvenience.

On his return to England, be obtained permission from the Lords Commissioners of the Admiralty to make a course of experiments in ships under their direction at the principal sea-ports, with a view to ascertain if compasses were similarly affected in other ships, and to try the general applicability of rules which he had found useful in correcting the errors in the Investigator. These rules, with the observations and reasonings on which they were founded, were published in a short paper in the Philosophical Transactions, and in a more detailed form in Appendix No. II. in the Voyage to Terra Australis. There are three points in these statements chiefly worthy of attention, from their practical importance; and on which it seems desirable, therefore, to notice how far his observations have been confirmed by those made in the Isabella and Alexander.

First; he found that in every ship a compass would differ very materially from itself, on being removed from one part of the ship to another. Experience of this source of irregularity had induced him, early in his voyage, to confine the use of the compass, with which his survey was carried on, to one particular spot. The place he selected was determined by convenience in other respects; it was on the binnacle, and exactly amidships.

The Isabella and Alexander had not completed half their voyage across the Atlantic, before it was found that the binnacle compasses of the one ship differed very materially, in indicating the course steered, from those of the other : namely, one point, or $11 \frac{1}{4}^{\circ}$. No dependance whatsoever could be placed on the agreement of compasses in different parts of the ship, or of the same compass with itself, if removed but a few inches: even in the neighbourhood of the binnacles the variation, as observed amidships, was from $8^{\circ}$ to $10^{\circ}$ greater than the result of azimuths taken by a compass placed between two or three feet on the larboard side; and an almost equal difference in a contrary direction took place on removing the compass to the starboard side, rendering it a matter of some trouble and difficulty, to make the azimuth compass agree with those in the binnacle by which the ship was steered, and for which it was therefore necessary to determine the variation.

As the ships ascended Davis's Strait, these latter compasses began to traverse so sluggishly, that it was necessary to shake the 
binnacles continually, to assist, their motion. 'The cards of these* had a metal rim round their circumference, weighing one ounce eleven drachuns. avoirdupois, which, as: the directive power of magnetism diminished, Lecame too heavy for the needle to sarry round: they were also frequently found to disagree with each other from $\frac{1}{4}$ to $\frac{3}{4}$ of a point ; the consequence, most probably, of the different local attraction to which they were exposed. These compasses ceased therefore to be attended to, except as an occasional assistance ta the helmsman, and a position was selected in each ship, in which a compass. on a more suitable construction was permanently fixed; by this the ship's course was directed, azimuths taken, and bearings of land, \&c. noted, during the voyage.

This standard compass, as it may be called, was placed in the Isabella exactly amidships, between the main and mizen mast, on a stout cross beam elevated nine or ten feet above the deck; this beam was the usual.walk of the Greenland pilot, or of the quarter master, as affording a better view of the ice among which the ships were frequently steered, than from the deck. The elevation was an advantage to the compass in such high magnetic latitudes, by rendering it less liable to accidental disturbance, on the removal of such implements of iron as were required to be kept on deck for use. The Alexander not having a similar cross beam, her compass was fixed amidships on a box of sand placed on the companion, between five and six feet, above the deek.

Secondly; Captain Flinders found that in his compass permanently fixed as described, no error took place when the ship's head was on the magnetic north or south points; showing, that at such times the attraction of the ship, and of magnetism, were in the same line of direction. The maximum of error also took place when the ship's head was at right-angles to these points; namely, at east or west; being however, in opposite directions, in excess of the true variation on the one side. and in defect on the other; so that the extreme difference occasioned by altering the course from east to west, or the reverse, would be twice the error at either.

On the intermediate points, the ratio of the error to its maximum, was. as the "sine of the angle between the ship's head and the magnetic meridian to the sine of eight points, or radius," or sufficiently near to admit of corrections being ealculated for every course, when the error on a single one was known by observation.

Thus far the experimente which Captain Flinders tried in every ship corresponded, excepting only that the maximum of error in different ships at the same place would differ materially.

- Burt's patent binnacle compasses. 
The aecordaniee in so thany ships gave him reason to believe that in compasses placed neat the bimnacle, and amidships, the points of no error'would be most commonly those of the maywetic metidian. Colisidering, however, that this must depend allogether on the distribution of iton, and inty be therefore liable to great diversity, he recommends that in every ship, as soon as a fixed position has been selected for a compass, the points of no errot: should be determined by wepeated otservation. The method that was adopted for this purpose in the late voyage appearing both. simple and'effectual, it may be wefal to exemplify itrby an instance on two.

Phe stabella being anchor in Brussa Sound, Shetland, her head was placed, by means of watps, oneach point of the compass saccessively, "and the beating of a pile of stortes on the summit of aslistant hil roted by her compass at exch point 1 at the same time that these olvservationis were made on board, her bearing from the hill was also observed by a compass placed on the pile of stones: the agrement in bearing showed the points of no error, and the differences the errors in each point; withnut the ealculation which azimuths involve.-[See Pl. IV. fig. 1.]

The Alexander being along side a foe of ice in Baffin's Bay, the true magnetic bearing from the ship, of a very distant and well defined object on the main land, was found by cartying a compass on the ice in an opposite direction, to a distance which ensured its being perfectly free from local influence. The ship's head being then warped round to each point of the compass successively; the errors in each were determined by the difference in bearing, as in the last instance.-[See. Pl. IV. fig. 2.]

The regularity in the above results is the best testimony that the method is a satisfactory one. Certain precautions must be attended to: thus, the object must be sufficiently distant, that the space occupied in warping the ship round may not subtend any sensible purallax. The direction of the ship's 'head should be noted by the coripass by whicli the bearings are taken. $\Lambda$ short time must he allowed to elapse after the ship is steady on any point, to ensure the traveroing of the cards : this is partichlarly necessary in high latitudes when the compasses move very sluggistly. And lastly, the observations should be repeated.

It will be observed by the above results, in the Fsabella and Alexarder; that the points of no error were not coincident in either ship with those of the magnetic metidian; in the Alexander especially, they were more nearly at right angles to it. That this ship should have differed so materially from all the instances on reeord, may be attributed to her compass being so near the level of the deck, and therefore being more affected by the influence of a considerable quantity of iron articles (such as ice anchors, 
ice saws, \&c.) which were carried on the after part of the deck for convenience in use, than it would have been, had it been raised higher. This was ployed by placing a compass on a plank elevated for experiment in front of the companion, to the same height as in the Isabella, namely, nine or ten feet. The points of no error were found, in this position, to be about north and south, sind the amount of error at eight points, nearly twenty degrees; the same as in the Isabella : the greatest error at the same time, by the Alexander's standard compass, viz. the one nearer the decks, being $8^{\circ} 20^{\prime}$ at N.N.E. The dip was $84^{\circ} 09^{\prime}$.

The propriety of Captain Flinders's recommendation, to determive, the points of no error in a fixed compass by actual observation in every ship as soon as the distribution of iron is completed, may therefore be considered as confrmed by the observations in the Isabella and Alexander; whilst his rule of proportion may recsive a verbal alteration to render it more suitable for general application: so corrected, it would be as follows-the expressions substituted being marked in italics, and the original words entered in the margin.

"The error produced in any direction of the East or west. ship's head, will be to the error at the point of the greatest irregularity, as the sine of the Magnetic meridian. angle between the ship's head and the points of no error to the sine of eight points, or radius."

Thirdly; Capt. Flinders's experience in the Investigator showed that the maximum of error in the same compass would be different in different parts of the world, although the use of the compass was confined to one particular spot in the ship, and every precaution taken to avoid an interference with the distribution of the ship's iron.

It is worthy of remark, that by multiplying observations and by comparing the series one with another, he was thus practically led to trace a connection between the amount of the errors and the dip of the needle; a knowledge of the fact preceding, in his mind, any theoretical suggestion that such might be the case.

It does not appear indeed that the principal cause of this connection was even subsequently known to him; he perceived that the infuence of local attraction on the compass needle increased as the dip became greater. He endeavoured to account for this circumstance, on a supposition that all iron might receive an $a b-$ solute increase in the intensity of its attractive power by approaching the magnetic pole.

The increase, however, which was the subject of his observation, was a relative one, being in comparison to the directive power of magnetism. A diminution in the latter would therefore produce the effect equally with an absolute augmentation in the for- 
mer; and that such a diminution does take place, and in a degree which is sufficient to account for all the effects observed, will be evident to every person, who reflects that although the magnetic force is greatest at the pole, its directive power must then have wholly ceased, having become less on the horizontal traversing of the needle in proportion as the point of attraction has been brought beneath the compass; indicated by the angle which the dipping needle makes with the horizon. This is doubtless the principal cause of the connection which Captain Flinders was the first to trace.

It is not designed to say that this cause may not be aided by the increased magnetism of portions of the ship's iron, such as bars and stanchions; which being fixed in an upright position, may receive an aldition to their attractive power where the position of the dipping needle is always coincident with theirs; but merely to observe, that a cause is known to exist for the connection, independently of supposition; which cause, conjointly with experience, shows the inadequacy of the rule proposed by Captain Flinders, whereby the amount of error, under any known dip, being ascertained, the amount may be calculated for any other dip, by using as a multiplier, the decimal expression of the proportion which the error, in the one ascertained instance, may have borne to the dip.

In the observations made in the Isabella at Shetland, where the dip is $74^{\circ} 21 \frac{1^{\prime}}{2}$, the maximum of error was $3^{\circ} 34^{\prime}$ easterly of the true variation, with the ship's head at E.S.E. and $5^{\circ} 46^{\prime}$ westerly at W.N.W. making an extreme difference of $11^{\circ} 20^{\prime}$.

By Captain Flinders's rule, the common multiplier for this compass would have been about one twelfth, or $\cdot 083$, which at a dip of $86^{\circ} 09^{\prime}$, which was the greatest observed during the late voyage, would have given an error of between $7^{\circ}$ and $8^{\circ}$, making the extreme difference $15^{\circ}$; whereas repeated observation showed it to be at that time more nearly $50^{\circ}$, if not exceeding that amount.

The inadequacy of the rule will also appear by reference to the observations made by the Alexander in Baffin's Bay. The error at eight points being $6^{\circ} 46^{\prime}$, at a dip of $84^{\circ} 30^{\prime}$; it ought scarcely to have exceeded $7^{\circ}$ at the greatest possible dip, making an extreme difference of less than $15^{\circ}$. No opportunity occurred indeed of making accurate observations at a greater dip than the above; but the difference in the bearing of objects before and after tacking indicated with sufficient certainty, that the error had increased to an amount very far beyond $15^{\circ}$; frequent instances of an extreme difference of from 3 to 4 points being remarked, as the ship approached the furthest western longitude to which she attained in a high latitude; this was in Lancaster's 
Sound of Baffin, into wlich inlet the expedition sailed beyont $81^{\circ}$ of west kougitude in the paratlel of $74^{\circ}$ and a few minutes.

It is much to be regretted that the service did not admit an opportunity to be afforded, of making observations on the various magnetic phromona, with the excellent fustruments supplied to the expedition, at this very interesting place; where a nearer approach was anade to one of the magnetic poles than had ever beell known before.

But in the absence of any actual observation on the dip of the needle, this fact of the error of the compasses having intreased from local attraction so greatly beyond the amount which had been hefore observed, is iworthy of notice, as affording an indieation that the dip had also increased, and not ineonsiderably. The greatest which was observed, was $86^{\circ} 09^{\prime}$; and after this observation, the ships continued to sail for six days in the direction in which the dip had hitherto been found to increase.

In concluding this paper, it may be permitted to remark, that it is to the voyages of discovery undertaken-during the reign of his present Majesty; that a knowledge of the extent and causes of the errors to which a compass is subject in ships, is to be principally attributed; as well as the steps that have been taken towards the investigation and remedy of the inconvenience they occasion to practical navigation.

The care and exertions of Captain Flinders in collecting observations for this purpose, give his opinions and rules a peculiar claim to attentive consideration. No one could have been more fully persuaded than he was, that a rule, founded on the effects experienced in a few ships, would require a far more extensive trial, before it could be depended on for general application.

'To carry this on, therefore, is to follow his useful example, and to effect what he was desirous to have done himself, had his life been spared.

XLVI. On the Anomaly in the Variation of the Magnetic Needle as observed on Ship-board. By Wir.LIAM SconesBy Jun., Esq. Communicated by the Right Hon. Sir Joseph Banks, Bart. G.C.B. P.R.S.*

$\mathbf{T}$

T $\mathrm{E}$ anomalies discovered in inagnetical observations conducted on ship-bnard, were usually attributed to the imperfection of the azimuth compass, until Captain Flinders, in his modest and enlightered paper on this subject, published in the Philosophical

* From Philosophical Transactions of the Royal Society for 1819, Part I.

Transactions, 